\title{
SOFRIMENTO ÉTICO E MORAL: UMA INTERFACE COM O CONTEXTO DOS PROFISSIONAIS DE ENFERMAGEM
}

\author{
Ethical and moral suffering: an interface with the context of nursing professionals
}

Souffrance éthique et morale: une interface avec le context des professionnelles infirmières

Sufrimiento ético y moral: una interfaz con el contexto de los profesionales de enfermeira

Erika Gonçalves Ambrósio 1

http://lattes.cnpq.br/4763936516818542.

Mestranda em Psicologia no Programa de Pós-Graduação em Psicologia na Universidade Federal do Rio de Janeiro (PPGP/UFRJ), especialista em Saúde da Família e Comunidade, na modalidade de Residência (HESFA/UFRJ) e Psicóloga formada no Instituto de Psicologia da UFRJ. Universidade Federal do Rio de Janeiro, Rio de Janeiro, Rio de Janeiro, Brasil.

\section{Vanessa Matos Lima ${ }^{2}$ \\ http://lattes.cnpq.br/8769534566569883.}

Mestranda no Programa de Pós-Graduação em Administração (PPGAd) na Universidade Federal Fluminense.

Pós-graduada em MBA Gestão de Recursos Humanos pela Universidade Federal Fluminense. Formada em Psicologia pelas Faculdades Integradas Maria Thereza. Atuante nas práticas de gestão de pes soas desde 2011. Universidade Federal Fluminense, Niterói, Rio de Janeiro, Brasil

\section{Elisete Soares Traesel $^{3}$ http://lattes.cnpq.br/6520509086117172.}

Doutora em Psicologia Social e Institucional pela Universidade Federal do Rio Grande do Sul. Docente adjunta em Psicologia Organizacional e do Trabalho da UFF-PUCG. Tem profunda experiência na área da Psicologia, com ênfase em Psicologia do Trabalho e das Organizações, Saúde do Trabalhador, Clínica do Trabalho, Psicodinâmica do Trabalho e em Subjetividade, Saúde e Processos Sociais na Contemporaneidade. Universidade Federal Fluminense, Niterói, Rio de Janeiro, Brasil

\section{Resumo}

Este artigo tem como objetivo relacionar os conceitos de sofrimento ético e moral às práticas dos profissionais de enfermagem, de forma a identificar como esses trabalhadores são afetados por tal sofrimento em situações relacionadas ao seu trabalho. Por meio de revisão bibliográfica foi possível, através de um breve esclarecimento teórico-filosófico das palavras ética e moral, obter maior entendimento epistemológico. Tendo como pano de fundo a teoria da Psicodinâmica do Trabalho, onde surge pela primeira vez o conceito sofrimento ético, foi possível realizar uma reflexão sobre o sofrimento do indivíduo ao negar a si e aos seus valores coma finalidade de realizar ou pactuar com ações que condena moralmente no seu trabalho. Ao abordarmos estudos que pesquisaram o sofrimento ético e moral em trabalhadores da saúde, sobretudo os de enfermagem, percebeu-se que os trabalhadores da área estão muito vulneráveis às escolhas que geram sofrimento ético, em decorrência do seu próprio trabalho de cuidador. Concluiu-se que, ainda que a maior parte da literatura abordada se utiliza do conceito de sofrimento moral, é possível relacionarmos este ao sofrimento ético e contribuir para ampliar as

\footnotetext{
1 erika.gambrosio@gmail.com

2 vanessa-matos@hotmail.com

3 etraesel@id.uff.br
} 
discussões e produções relativas à temática, tendo em vista seu impacto sobre a saúde mental desses profis sionais.

Palavras-chave: Sofrimento Mental; Saúde do Trabalhador; Cuidados de Enfermagem; Ética; Moral.

\begin{abstract}
This article aims to relate the concepts of ethical and moral suffering to the practices of nursing professionals, in order to identify how these workers are affected by this suffering in situations related to their work. Through a bibliographical review it was possible, through a brief theoretical and philosophical clarification of the words ethics and morals, to obtain a greater epistemological understanding. Having as backdrop Psychodynamics of Work, where the concept of ethical suffering arises for the first time, it was possible to think over the suffering of the individual by denying himself and his values for the purpose of performing or negotiating with actions that morally condemned at work. When we approached studies that investigated the ethical and moral suffering of health workers, especially nursing workers, it was noticed that workers in the area are very vulnerable to the choices that generate ethical suffering as a result of their own caregiver work. It was concluded that, although most of the literature covered uses the concept of moral suffering, it is possible to relate this to the ethical suffering and contribute to broaden the discussions and productions related to the theme, considering its impact on mental health these professionals.
\end{abstract}

Keywords: Mental Suffering; Occupational Health; Nursing Care; Ethics; Morale.

\title{
Résumé
}

Cet article vise à relier les concepts de souffrance éthique et morale aux pratiques des infirmières professionnelles, afin de déterminer comment ces travailleuses sont affectées par cette souffrance dans des situations liées à leur travail. Grâce à une revue bibliographique, il a été possible, une brève clarification théorico-philosophique des mots éthique et morale, d'obtenir une meilleure compréhension épistémologique. Dans le contexte de la théorie de la Psychodynamique du Travail, où le concept de souffrance éthique est apparu pour la première fois, il a été possible de réfléchir à la souffrance de lindividu en se niant lui-même et ses valeurs dans le but d'accomplir ou de moralement condamné au travail. Lorsque nous avons abordé des études portant sur les souffrances éthiques et morales des personnels de santé, en particulier des infirmiers, il a été constaté que les travailleurs de la région sont très vulnérables aux choix qui génèrent des souffrances éthiques du fait de leur propre travail de soignant. Il a été conclu que, bien que la plupart des ouvrages abordés utilisent le concept de souffrance morale, il est possible de le relier à la souffrance éthique et de contribuer à élargir les discussions et les productions liées au thème, compte tenu de son impact surla santé mentale. ces professionnels.

Mots-clés: Souffrance Mentale; Santé au Travail; Soins Infirmiers; Éthique; Morale.

\section{Resumen}

Este artículo tiene como objetivo relacionar los conceptos de sufrimiento ético y moral a las prácticas de los profesionales de enfermería, para identificar cómo esos trabajadores son afectados por ese sufrimiento en situaciones relacionadas a su trabajo. Por medio de revisión bibliográfica fue posible, a través de un breve aclaramiento teórico-filosófico de las palabras ética y moral, obtener mayor entendimiento epistemológico. Com la ayuda de la teoría de la Psicodinámica del Trabajo, donde surge por primera vez el concepto sufrimiento ético, fue posible realizar una reflexión sobre el sufrimiento del individuo al negarse a sí ya sus valores con la finalidad de realizar o pactar con acciones que, condena moralmente en su trabajo. Al abordar estudios que in vestigó el sufrimiento ético y moral en trabajadores de la salud, sobre todo los de enfermería, se percibió que los trabajadores del área están muy vulnerables a las elecciones que generan sufrimiento ético, como consecuencia de su propio trabajo de cuidador. Se concluyó que, aunque la mayor parte de la literatura abordada se utiliza del concepto de sufrimiento moral, es posible relacionar esto al sufrimiento ético y contribuir a ampliar las discusiones y producciones relativas a la temática, teniendo en cuenta su impacto sobre la salud mental de estos profesionales.

Palabras clave: Sufrimiento Mental; Salud Laboral; Atención de Enfermería; Ética; Moral. 


\section{INTRODUÇÃO}

A construção do conceito de ética e moral perpassa por análises semânticas e filosóficas. Ao abordar essas perspectivas, é possível nos deparar com diferentes autores que se debruçaram na tentativa de explicar a aplicabilidade da ética e moral na vida cotidiana.

Com relação ao sofrimento ético, este conceito nasce dentro da abordagem da Psicodinâmica do Trabalho, cujo teórico fundador e mais conhecido é Christophe Dejours. A primeira menção ao termo ocorreu em 1999, no livro A Banalização da Injustiça Social e, no mesmo ano, no artigo Violence ou domination? O autor salienta que a Psicodinâmica do Trabalho é uma disciplina clínica e teórica, que busca conhecer e descrever as relações entre trabalho e saúde mental, assim como relacionar esses resultados às teorias científicas.

Dejours (2004a) nos aponta, ainda, a importância de buscarmos, junto aos trabalhadores, construir conhecimentos e contribuições que sejam significativas para eles e que possam influenciar em sua saúde mental, no sentido de transformação do sofrimento inerente ao trabalhar em prazer. Propomos, em conjunto, a superação da lógica de proteção do resultado do trabalho, ou seja, de uma saúde da produção, para a saúde dos próprios trabalhadores.

Nesse sentido, o sofrimento ético se caracteriza como aquele experimentado quando o sujeito comete, negligencia ou compactua com atos com os quais não concorda e condena moralmente (Dejours, 2006). Segundo sua teoria, conforme as possibilidades que a organização do trabalho permite para o uso de mecanismos defensivos individuais, estratégias coletivas e ações de mobilização dos trabalhadores, são possíveis aos sujeitos manterem-se em um estado de normalidade diante das contradições da organização. $\mathrm{Na}$ perspectiva do autor, é possível ainda a transformação desse sofrimento em prazer, com grande influência da cooperação no uso das inteligências individuais e com o reconhecimento advindo do coletivo.

Pesquisas abordando o sofrimento no trabalho estão presentes nos mais diversos campos relacionados à temática. Enquanto o conceito de sofrimento moral parece bastante estudado pelos profissionais da saúde e dentre eles, destacadamente, os da enfermagem, tanto na perspectiva de pesquisar e intervir junto às outras categorias profissionais como no seu próprio corpo de trabalhadores, as pesquisas envolvendo o conceito de sofrimento ético parecem mais escassas. Surge, assim, a necessidade de entender quais fatores podem estar associados à experiência de sofrimento ético e moral pelos profissionais de saúde, especialmente os da enfermagem. 
A experiência de sofrimento, abordada pela Psicodinâmica do Trabalho como sofrimento ético, pode ser assemelhada ao conceito de sofrimento moral amplamente pesquisado no âmbito dos profissionais de enfermagem. Tendo em vista o seu dia a dia como trabalhador cuja principal função é prestar cuidado em saúde a outras pessoas, é preciso possibilitar um espaço de discussão sobre a saúde desses profissionais, a fim de compreender qual o seu real papel nas variadas situações de trabalho. Isso inclui uma análise que contemple as demandas institucionais que exigem, diariamente, práticas dos trabalhadores que se opõem ou negam seus valores e crenças pessoais, assim como as consequências desse movimento de agir ou pactuar com ações que condenam, tendo em vista que a organização do trabalho não proporciona espaço para apontamentos ou reflexões sobre tais sofrimentos, de maneira a perpetuar sua ação negativa sobre a saúde dos trabalhadores.

Nesse sentido, este artigo objetiva relacionar os conceitos de sofrimento ético e moral às práticas dos profissionais de saúde do campo da enfermagem. Espera-se aumentar a visibilidade do tema dentro desta categoria profissional, assim como ampliar a produção de conhecimento científico sobre o tema abordado. Ressalta-se a pouca bibliografia disponível sobre o conceito de sofrimento ético na perspectiva da teoria da Psicodinâmica do Trabalho e busca-se uma articulação com a bioética, para a proposição de intervenções eticamente responsáveis e relacionadas à saúde dos trabalhadores.

\section{MATERIAIS E MÉTODOS}

Esta pesquisa se orienta a partir de uma análise epistemológica construtivista que, segundo Saccol (2009), supõe que o conhecimento humano advém da interação entre pessoas e o mundo. Logo, entendemos que o conhecimento produzido é contextualizado a partir de uma interação que esteja inserida em um determinado contexto social que, portanto, deve ser propriamente analisado. Utilizamos como método de busca e análise dos resultados a revisão bibliográfica de textos científicos, dentre os quais se encontram artigos científicos, dissertações, teses e livros. As referências para os achados teóricos em meios virtuais foram coletadas entre os dias 11 de maio de 2018 e 10 de julho de 2018, através da busca nas plataformas Scielo, Biblioteca Virtual em Saúde (BVS) e Google Acadêmico, a partir dos seguintes descritores e suas combinações: "sofrimento ético", "sofrimento moral", "psicodinâmica do trabalho", "sofrimento ético e moral", "sofrimento", "ética e moral", "sofrimento no trabalho" e "clínica do trabalho". 
Dentre as publicações coletadas, foram selecionadas para esta pesquisa aquelas cujo texto integral estivesse disponível para consulta e análise, e aquelas que, após a leitura do resumo, guardassem alguma relação com o tema pesquisado, a saber, o sofrimento ético e moral presente nas relações de trabalho de enfermeiras e enfermeiros. $\mathrm{O}$ artigo mais antigo obtido com base nesses critérios de inclusão foi publicado em 2004 e os dois mais recentes em 2017. Enquanto os achados contabilizam oito publicações feitas entre 2004 e 2010, foram coletados dez artigos com publicação entre 2011 e 2017, com maior recorrência de publicações realizadas no ano de 2014 , cuja busca resultou em quatro textos.

De forma complementar, foram utilizadas bibliografias de apoio para contextualizar as discussões sobre os conceitos de ética e moral, a teoria da Psicodinâmica do Trabalho e sobre as possíveis articulações com a bioética para a proposição de práticas organizacionais mais saudáveis e produtoras de vida, possibilitando assim maior entendimento global sobre a temática da pesquisa e suas proposições.

\section{RESULTADOS E DISCUSSÃO}

Com base nas expressões utilizadas nas plataformas online de pesquisa e os critérios de inclusão, foram encontrados 18 trabalhos, dentre eles 13 artigos, 1 tese de doutorado completa, 1 tese de doutorado resumida, 1 trabalho de conclusão de especialização, 1 livro completo e 1 capítulo de livro. Das dezoito referências, oito, ou seja, quase $50 \%$ dos resultados, referem-se ao trabalho da enfermagem, sendo uma dessas publicações um estudo que analisa conjuntamente o trabalho de guardas municipais. Contudo, também foram encontradas pesquisas sobre o trabalho de atendentes de um call center (uma), oficiais de justiça (uma), trabalhadores em geral (uma) e trabalhadores da saúde (duas), além de pesquisas teóricas sobre os conceitos de ética e moral (quatro) e sofrimento no trabalho (uma).

As publicações pertencem, predominantemente, às revistas do campo da Psicologia (seis), seguidas de publicações de Enfermagem (quatro), Filosofia (três), Ciências da Saúde (duas) e Saúde Coletiva, Saúde Ocupacional e Trabalho (cada campo com uma publicação). A expressão 'sofrimento ético' foi encontrada em somente duas referências, sendo mais comum o uso de expressões como dilemas, questões e conflitos éticos, problemas éticos e sofrimento moral.

Os resultados serão apresentados em três grandes categorias, dividindo-se entre aqueles mais concernentes à conceituação dos termos ética e moral, e como podemos entender sua aplicação no cotidiano; resultados que ajudam a refletir e discutir o tema a partir da 
perspectiva teórica da Psicodinâmica do Trabalho; e materiais que abordem o sofrimento ético e moral nas práticas dos profissionais da enfermagem.

\section{Contorno semântico e filosófico dos termos Ética e Moral}

Ética e moral são termos utilizados por alguns autores como sinônimos. Entretanto, apesar de serem constituintes e constituídas, outros estudiosos conseguem diferenciá-las mesmo que estejam em uma mesma dimensão filosófica. Segundo o dicionário Houaiss (2001) da Língua Portuguesa, éthos significa "o conjunto dos costumes e hábitos fundamentais, no âmbito do comportamento (instituições, afazeres etc.) e da cultura (valores, ideias ou crenças), característicos de uma determinada coletividade, época ou região".

A palavra ética tem como origem a palavra grega éthos, a priori designada à morada dos homens e dos animais. É através desta significação que a palavra éthos se origina como costume, estilo de vida e ação. A partir desta construção de significado semântico é possível alcançar o uso empregado à palavra ética, que tem como objetivo a práxis. Desta maneira é concebível perceber a relevância dada para o agir humano, a realização do "bem" na vida individual e grupal por meio fundamentados em valores e princípios que possam tornar a vida humana mais agradável (Vaz,1999).

O termo moralis como tradução de ethiké demonstrado em um latim tardio foi utilizado como adjetivo para a Filosofia Moral e como substantivo na língua corrente, tal como é empregada nos dias atuais. Vaz (1999) destaca que mesmo tendo como raiz a palavra grega éthos, o uso do vocabulário moral é ampliado em seus significados e aplicabilidade. Seu uso é aplicado em expressões como vontade, desejo, hábito, natureza, lei, regras, entre outros aspectos advindos do comportamento ou atitude.

Através da origem semântica dos termos Ética e Moral, Lima Vaz nos demonstra que:

a evolução semântica paralela de Ética e Moral a partir de sua origem etimológica não denota nenhuma diferença significativa entre esses dois termos, ambos designando fundamentalmente o mesmo objeto, a saber, o costume socialmente considerado, seja o hábito do indivíduo de agir segundo o costume estabelecido e legitimado pela sociedade.(Vaz, 1999).

A filosofia moderna, para além da análise semântica, é responsável pelas discussões empregadas ao uso prático dos termos citados. Segundo Cerqueira (2006), Adam Smith, economista e filósofo escocês, inicia em seu livro Teoria dos Sentimentos Morais, uma análise própria do julgamento moral focada em uma visão do homem e suas interações interpessoais, do que é importante e gera significado para o mesmo, do que o motiva ou não, 
dos causadores de prazer ou dor. Adam Smith constrói sua teoria com base na empatia humana, em que tal comportamento traz a consciência e moralidade dos próprios comportamentos.

Por mais egoísta que se suponha o homem, evidentemente há alguns princípios em sua natureza que o fazem interessar-se pela sorte de outros, e considerar a felicidade deles necessária para si mesmo, embora nada extraia disso senão o prazer de as sistir a ela. (Smith, 2002, p. 5).

A moral para o autor não é medida exclusivamente pela razão, pelo contrário, a mesma se constitui nas relações subjetivas entre o próprio indivíduo e o outro, na medida em que os sentimentos são constituídos de forma pessoal e influenciados pelos sentimentos de terceiros. "Como não temos experiência imediata do que outros homens sentem, somente podemos formar uma ideia da maneira como são afetados se imaginamos o que nós mesmos sentiríamos numa situação semelhante" (Smith, 2002, p. 5-6). É possível identificar dentre as colocações do autor diretrizes que envolvem um julgamento interno e externo, em que o outro é agente importante como influenciador, mas que não retira a autonomia do indivíduo que é influenciado. "[...] empenhamo-nos em examinar nossa própria conduta como imaginamos que outro expectador imparcial e leal a faria" (Smith, 2002, p. 140).

Em outro olhar sobre a ética, o filósofo Kant (1964) afirma que existe uma razão prática pura, uma razão independente das experiências corpóreas, sensíveis. A lei moral só pode ser compreendida pela razão prática pura, ou seja, uma razão independente e totalmente desvinculada dos afetos, do corpo e das próprias paixões; uma razão intrínseca a todos os indivíduos. Segundo Kant a razão prática pura é fundamental para a construção do sujeito moral. A ética do dever afirma que é necessária uma rejeição completa dos prazeres no momento em que é determinada uma ação moral, tendo em vista que os prazeres são oriundos do corpo, ou seja, que advém da própria percepção sensível. Para o autor, na investigação das leis morais, as religiões e a cultura devem ser desconsideradas, pois apenas é possível compreender a ação moral pela razão prática pura. O imperativo categórico age de tal modo em que sua ação possa se tornar uma lei universal.

Uma vez que são determinadas as leis absolutas da moral, é necessário segui-las em todas as circunstâncias, pois estas são determinantes, independente dos sentimentos envolvidos. A "lei fundamental da razão prática pura: age de tal modo que a máxima da tua vontade possa valer sempre ao mesmo tempo como princípio de uma legislação universal" (Kant, 1989, p. 42). Desta forma pressupõe-se que a liberdade é apenas possibilitada no indivíduo moralmente forjado pela razão prática pura e não poderá ser exercida pelo indivíduo 
estritamente inclinado a seus fundamentos subjetivos. Eis que o autor tem como objetivar e universalizar a liberdade.

No que se refere ao sofrimento ético e moral, Dejours (1999) através da Psicodinâmica do Trabalho destaca que realizar ações que são desaprovadas pelo próprio sujeito que as executa gera um tipo de sofrimento, nomeado pelo autor como sofrimento ético. Este sofrimento é desencadeado na medida em que o sujeito não concorda com a execução de uma tarefa, porém mesmo assim a realiza. Freud (1974) em O mal-estar da civilização, relata que uma grande parcela da população trabalha sob extrema necessidade, e que tais pessoas veem o trabalho como atividade digna de aversão. Entretanto o autor salienta que essa mesma atividade pode ser vista como fonte de satisfação se for escolhida de forma livre através da sublimação. Desta maneira a busca incessante pelo prazer no trabalho esbarra na fuga do desprazer. Entre estes processos está um trabalhador portador de desejos, história de vida e crenças, que por muitas vezes na relação com outro e na organização do trabalho realiza exigências contrárias às suas próprias convicções.

\section{Reflexão e discussão na perspectiva da Psicodinâmica do Trabalho}

A Psicodinâmica do Trabalho é uma abordagem teórico-metodológica multiprofissional e interdisciplinar, cujo principal autor é o médico francês Christophe Dejours. Seu trabalho inicial se alocava no âmbito da Psicopatologia do Trabalho, disciplina originada nas décadas de 1950/1960, fortemente influenciada por autores como Guillant, Veil, Sivadon, Fernandez-Zoila e Bégoin (Dejours, 2004a).

Segundo Martins (2009), o autor iniciou suas pesquisas com a disciplina da Psicopatologia do Trabalho em 1973, buscando mostrar como os sujeitos se relacionam com uma organização do trabalho inflexível, assim como as formas de sofrimento e adoecimentos derivados dessa relação e seu conteúdo. Nas décadas de 80 e 90, o autor amplia o seu leque de pesquisas, deslocando o foco da psicopatologia para a normalidade, entendida como um processo dinâmico, instável, complexo e intersubjetivo entre sofrimento e prazer no trabalho, e também passa a compreender que as organizações são passíveis de transformação. Tal mudança parte das experiências dos pesquisadores e dos questionamentos acerca da massa de trabalhadores que não adoecia em decorrência do trabalho. Assim, tanto as pesquisas foram se modificando, quanto a nomenclatura da abordagem, que passou a ser denominada Psicodinâmica do Trabalho (Dejours, 2004a). 
A produção científica sob a perspectiva desta abordagem se proliferou no Brasil e no mundo, contando com contribuições importantes dos campos da sociologia, economia e psicanálise, dentre outros. Para Dejours (2004b, p.28), "trabalho se define como sendo aquilo que o sujeito deve acrescentar às prescrições para poder atingir os objetivos que the são designados." O autor ainda acrescenta que trabalhar, isto é, essa ação de um sujeito no mundo pode ser definida também como aquilo que o trabalhador acrescenta a si ao enfrentar o sofrimento decorrente do encontro com o real que não se resume ao que é tecnicamente prescrito. É central, portanto, para a Psicodinâmica do Trabalho, a noção da discrepância entre o trabalho prescrito - aquele regido por normas, regras e procedimentos que orientam como cada tarefa deve ser efetuada para que se alcance a qualidade do produto final, e o trabalho real, que é singular, imprevisto e criativo, haja vista que resulta de uma construção dos sujeitos em suas situações de trabalho.

O trabalho, além de uma experiência singular, também tem um importante fator social, de convivência; trabalhar envolve colocar-se num mundo compartilhado, socialmente desigual, hierarquizado e com disputas de poder e dominação. A experiência de desencontro da realidade com as prescrições na organização do trabalho e as relações sociais atinge o trabalhador pela via do afeto, com sentimentos de impotência, irritação e decepção, ou seja, pela experiência afetiva de sofrimento. Nessa dinâmica, a história de cada trabalhador e sua maneira de apropriar-se do mundo e de sua subjetividade levam-no a vivenciar esse sofrimento de uma forma singular (Martins, 2009). Entretanto, ainda que trabalhar seja, em primeira instância, experienciar o sofrimento, este não contribui exclusivamente para as diferentes formas de adoecimento, podendo ser também um "ponto de partida" para outros destinos possíveis, como a inteligência e a própria subjetividade do trabalhador (Dejours, 2004b).

Esse outro destino possível para o sofrimento no trabalho pode surgir por meio de sua utilização para a construção de estratégias de enfrentamento, tanto para a proteção do trabalhador quanto para a transformação das situações que o provocaram (Mendes, Costa e Barros, 2003). Tais estratégias podem ser mobilizações subjetivas ou estratégias defensivas individuais e coletivas.

Mendes (1995, p. 37) conceitua mobilização subjetiva como "processo que se caracteriza pelo uso da inteligência operária e pelo espaço público de discussões sobre o trabalho." Assim, a transformação do sofrimento em prazer passa pelos três componentes irredutíveis do trabalho: a atividade produtiva, a mobilização subjetiva e a coordenação entre as atividades do coletivo. Desta forma, por meio da mobilização subjetiva, ao ter capacidade 
de tolerar o sofrimento, o sujeito utiliza-o para guiar sua inteligência, para que possa encontrar, na prática, maneiras criativas de superá-lo. Com contribuições que partem da sua própria subjetividade e do coletivo de trabalho, por meio da cooperação e do reconhecimento, o sentimento de sofrimento pode tornar-se criativo, levando ao sentimento de prazer (Martins, Moraes e Cruz Lima, 2010). Este movimento de transformação das vivências dolorosas em prazer possibilitaria o sofrimento criativo, mediador de saúde e realização.

Outra forma de lidar com o sofrimento relativo ao trabalho e seus efeitos negativos sobre sua saúde é por meio de estratégias defensivas, individuais ou coletivas, uma vez que elas são um "mecanismo pelo qual o trabalhador busca modificar, transformar e minimizar sua percepção da realidade que o faz sofrer" (Mendes, 1995, p.38). Através das estratégias defensivas, é possível ao trabalhador ou ao seu coletivo de trabalho diminuir a percepção do sofrimento e permitir a manutenção de uma normalidade de trabalho (Moraes, 2013).

Entende-se, portanto, que o sofrimento se torna patogênico quando a organização do trabalho não possibilita ao trabalhador realizar essas operações de resistência e superação do sofrimento do encontro com o real, quando há pouco sentimento de cooperação entre o coletivo de trabalho ou ainda quando a dinâmica do reconhecimento não ocorre (Dejours, 2007). Dessa maneira, o sofrimento se prolonga diante do esgotamento do sistema defensivo e contribui para o adoecimento psíquico e/ou físico.

Há, na Psicodinâmica do Trabalho, um terceiro tipo de sofrimento, o sofrimento ético. Esse conceito começou a ser abordado nas obras publicadas por Dejours em 1999, aparecendo primeiramente no livro A Banalização da Injustiça Social e depois no artigo Violence ou domination? No livro, o autor busca discutir a questão da prática, do consentimento e da vivência de violência, especialmente no contexto do trabalho, a partir de uma leitura crítica do discurso neoliberal que se impõe como uma ideologia única, ou seja, o discurso neoliberal, de cunho eminentemente economicista e desumano, parece ser o único que é aceito e por ele mesmo justificável. Nesta obra, o autor conceitua como sofrimento ético "não o sofrimento que resulta de um mal padecido pelo sujeito, e sim o que ele pode experimentar ao cometer, por causa de seu trabalho, atos que condena moralmente" (Dejours, 2006, p.36). Segundo Vasconcelos (2013), essa definição nos aponta que, para além do sofrimento de quem sofre diretamente a violência, o sofrimento ético pode se manifestar em todos os demais envolvidos na situação, ou seja, naqueles que causam, consentem e/ou se omitem.

Em Violence ou domination? Dejours (1999) aponta que, por meio da dominação simbólica, isto é, de um discurso social proposto pelo sistema econômico neoliberal como forma única e verdadeira de olharmos o mundo, novas formas de sofrimentos estão presentes 
na sociedade, e em consonância, nas situações de trabalho, haja vista que seriam justificáveis certas formas de gerir o trabalho e a sociedade. Uma vez que esse discurso se constrói consistente do ponto de vista racional e se propaga como mais verdadeiro que os demais, ele age sobre a sociedade, disfarçando ações violentas e desqualificando suas vítimas e as pessoas que testemunham essa violência. E devido à sua força, esse discurso adquire status de unicidade, ou seja, ele influencia, ainda que de maneira singular, a todos.

Essa dominação simbólica, ao esconder ações de violência que causam sofrimento, auxilia no processo de individualização e de tolerância à injustiça e sofrimento. Nesse sentido, os processos de dominação simbólica geram situações de violência, injustiça e ameaça de exclusão social, e podem ser palco para vivência de sofrimento ético ou de perpetuação de vidas descartáveis (Santos, 2007), que seriam vidas utilizadas pelo discurso economicista e racionalista no processo produtivo como recursos para a acumulação e lucro.

No que se refere aos aspectos bioéticos subjacentes às ações de violência sócio laboral, Lins, Vasconcellos e Palacios (2015), apoiados no pensamento de Garrafa e Porto (2003), afirmam que, quando inserida no contexto dos países periféricos, a bioética destaca questões pertinentes e recorrentes a esse contexto. Desta forma, dividem os problemas morais em dois grupos, os persistentes e os emergentes. Os persistentes se apresentam há mais tempo no âmbito do trabalho. "Como exemplos, temos, entre outros: assédio moral, sexual e racial no contexto do trabalho; deontologias profissionais e seus limites" (Lins, Vasconcellos e Palacios, 2015, p.296).

Os problemas morais emergentes têm como principal fonte geradora o meio biotecnocientífico no trabalho, e são exemplificados com "aprimoramentos neurocognitivos concernentes ao trabalho; modificações de funções e características corporais voltadas para o trabalho; medicalização da vida em função do trabalho" (Lins, Vasconcellos e Palacios, 2015, p.296). Tendo em vista os dois olhares distintos, é possível entender a bioética através de perspectivas diversas, mas com o objetivo comum de enxergar como prioridade a saúde do trabalhador. Entretanto, essa prioridade com frequência não é colocada em ação no meio empresarial.

No tocante às organizações, alguns autores apontam a existência de uma ética empresarial que se volta para a aplicação de um discurso racionalista aplicado às questões e situações éticas no trabalho, que podem ser no nível das relações internas, perpassando questões como a corrupção, abusos, assédio e exploração do trabalho, ou que podem repercutir ainda externamente, como danos às comunidades e ao meio ambiente. (Lins, Vasconcellos e Palácios, 2015). Para lidar com esses exemplos, as direções gerenciais criam 
códigos de ética ou códigos de condutas sem a participação e deliberação coletiva dos trabalhadores e que não abordam os problemas e contradições do trabalho real, sendo impostos no intuito de operacionalizar as práticas dos trabalhadores para a resolução destas situações de forma menos custosa e mais rentável para o processo produtivo, ou seja, buscam operar uma saúde da produção que não faz eco na promoção de saúde dos trabalhadores.

Caso a vivência de sofrimento ético seja alvo de estratégias defensivas, os trabalhadores, ao se depararem com situações que condenam moralmente, podem tornar-se indiferentes (Vasconcelos, 2013), devido ao medo de agir em virtude da ameaça de exclusão social e precarização das situações de trabalho. Tendo em vista que essas estratégias buscam minimizar ou negar o sofrimento, o sujeito pode tornar-se indisponível, insensível e intolerante ao sofrimento experienciado, e indiferente a sua causa (Dejours, 2006). Assim, numa tentativa de alcançar a normalidade no trabalho, os trabalhadores podem banalizar as situações de violência e injustiça. Esse impedimento de afetar-se pela situação e a partir dela indignar-se pode levar os trabalhadores ao adoecimento, uma vez que perdura o sofrimento ético, sem a possibilidade de transformá-lo.

Por outro lado, o sofrimento ético pode levar à mobilização do sujeito para o enfrentamento da situação que o causa. Ao deparar-se com o sofrimento e com ele indignarse, o trabalhador está ativamente construindo formas de ação que podem levar a uma luta pela diminuição das causas do sofrimento e pela busca da normalidade, do prazer e da saúde. Assim, é por meio da indignação de alguém ou de um coletivo que causa ou testemunha uma violência ou injustiça que o sofrimento ético pode ser transformado, através da mobilização, em ação de modificação da situação que o originou (Vasconcelos, 2013).

O trabalho, portanto, tem um papel central na constituição da subjetividade e da saúde mental dos sujeitos. Enquanto a saúde pode ser definida como um equilibrio dinâmico das vivências de prazer e sofrimento, junto com a capacidade de mobilização para uma relação gratificante com o trabalho e da dinâmica do reconhecimento (Mendes, 2007, p. 46), o adoecimento seria sua impossibilidade ou o desequilibrio dinâmico das experiências de sofrimento frente às de prazer.

A partir dos conceitos expostos, com base na perspectiva da Psicodinâmica do Trabalho, fica evidente a importância da realização de pesquisas baseadas nas experiências dos próprios trabalhadores, mais do que numa racionalidade técnica gerencial. Assim, é possível construirmos formas de buscar entender a mediação que o sofrimento faz no processo de saúde-adoecimento e na constituição da própria subjetividade, de forma sempre dinâmica e singular. Aproximamo-nos, nesse ponto, de Maturana (2002), autor que aborda a importância 
das emoções na educação e política, à medida que afirma que a ética na sociedade ocidental se sustenta a partir de uma perspectiva racionalizante, isto é, somente baseada na racionalidade e nos discursos que com ela conversam. Contudo, essa abordagem se mostra excludente, à medida que desconsidera a emoção como componente de uma análise real e propositiva das questões, impedindo uma análise mais integral da realidade vivenciada.

Apesar da organização de trabalho ter caráter coletivo, permitindo aos trabalhadores experiências em comum no seu fazer, são partes importantes da análise psicodinâmica a experiência individual e as formas como as defesas e engajamentos da subjetividade se diferenciam em cada sujeito em cada situação. Assim, entende-se que incluir os afetos, os discursos heterogêneos, as normas explícitas e todos os componentes de uma situação real nos permitem acessar mais integralmente a experiência e buscar intervenções que encontrem ressonância com a realidade vivenciada pelos trabalhadores.

Destacam-se ainda as diferenças de conceituação do sofrimento, de acordo com o destino que o mesmo adquire nesse processo que perpassa a subjetividade de cada trabalhador, ou seja, a mobilização subjetiva, defesas individuais e coletivas, reconhecimento, cooperação e afetos advindos dessas situações de trabalho. Desta forma, ele pode tornar-se criativo, pela possibilidade de uso da criatividade e inteligência prática; patogênico, quando ultrapassa as possibilidades de defesa e enfrentamento dos sujeitos; ou ético, quando envolve realizar, ser expectador ou negligenciar ações que a sociedade ou a organização do trabalho exigem em suas práticas, ainda que formalmente as condene, havendo, portanto, desencontro entre os valores éticos individuais e as ações efetuadas.

O sofrimento ético, com conceituação mais recente, é o menos abordado na literatura referente à teoria da Psicodinâmica do Trabalho. Entretanto, é possível identificarmos, a partir das conceituações de sofrimento moral e ético que iniciam este artigo e das reflexões a partir da Psicodinâmica do Trabalho, nos estudos que abordam o trabalho dos profissionais de enfermagem situações que sinalizam a presença de sofrimento ético. Assim, abordaremos a seguir pesquisas que tratam de uma análise do trabalho dessa categoria, buscando refletir como elas expõem situações de relacionadas ao conceito de sofrimento ético, e quais as repercussões destas na saúde destes trabalhadores. 


\section{O sofrimento ético e moral nas práticas dos profissionais da enfermagem: repercussões e estratégias de enfrentamento:}

Dentre os artigos da categoria que aborda o sofrimento moral e que aqui serão discutidos, destaca-se que a abordagem é mais presente nos profissionais e pesquisadores de enfermagem. Nesse sentido, Fruet, Dalmolin e Speroni (2017), pautados em uma revisão bibliográfica, identificam a Moral Distress Scale (MDS) como instrumento mais utilizado para avaliação do sofrimento moral para trabalhadores de enfermagem na literatura nacional e internacional. De origem norte-americana e com uma versão adaptada à realidade brasileira, o instrumento torna-se importante à medida que possibilita, além da avaliação do sofrimento moral na categoria, a construção de estratégias de proteção frente ao fenômeno e a facilitação de deliberações que contenham questões morais importantes para o exercício profissional (Fruet, Dalmolin e Speroni, 2017).

O sofrimento moral é uma categoria que compõe os problemas éticos que afetam os profissionais de enfermagem. Estes problemas podem ser de três tipos: sofrimento moral, quando os trabalhadores sentem-se impedidos de agir conforme seus valores e de maneira eticamente apropriada por medo de represálias ou dificuldades individuais, e cujas consequências podem atingir negativamente a sua subjetividade; a incerteza moral, quando o modo ético de agir não está facilmente identificado, mas há uma sensação de incerteza, tensão e incômodo quanto ao curso adotado; e, por fim, os dilemas morais, quando o trabalhador, diante de duas ou mais formas igualmente éticas de agir, vê-se num processo de escolha (Dalmolin, Lunardi, Lunardi, Barlem \& Silveira, 2014). Desta forma, através de diversas situações que envolvem esses trabalhadores, com suas dificuldades individuais de enfrentamento do sofrimento, além de suas relações institucionais com os pacientes, familiares e demais profissionais de saúde, é possível que os profissionais tenham ou não clareza das situações em que problemas éticos acontecem.

Os autores ressaltam, como resultado da pesquisa, que as situações de sofrimento moral, relacionadas, sobretudo, à prática de procedimentos que esses trabalhadores consideram desnecessárias, fúteis e prolongadoras de sofrimento em pacientes terminais relacionam significativamente sofrimento moral e a síndrome de Burnout, descrita como um "fenômeno complexo e multifacetado que afeta os aspectos do bem-estar dos trabalhadores da saúde e a qualidade do atendimento prestado" (Dalmolin et al, 2004, p.2). Assim, é possível aproximarmos as ações de trabalho nessas situações, contrárias aos valores e conhecimentos dos profissionais que as executam a mando de outros, com as situações onde estaria presente 
o sofrimento ético, conforme definido na Psicodinâmica do Trabalho, abordado anteriormente.

Lunardi, Barlem, Bulhosa, Santos, Filho, Silveira, Bao \& Dalmolin (2009), ao abordarem situações de sofrimento moral dos trabalhadores de enfermagem em ambiente hospitalar, afirmam que este sofrimento pode resultar em diferentes situações, a depender de quais estratégias serão adotadas pelos trabalhadores. De forma defensiva, a subjetividade engajada no cuidado pode ser modificada, de maneira a afastar o doente e o sofrimento derivado de sua situação. Além disso, os efeitos negativos incluem sintomas físicos e psíquicos, como insônia, ansiedade, incapacidade de concentração, maior suscetibilidade a doenças laborais e depressão. Os resultados nos trabalhadores podem ainda envolver sentimentos de medo, culpa, fraqueza, raiva, e de falta de suporte moral e profissional.

Outro ponto importante destacado aponta que o ambiente hospitalar, ou seja, a organização do trabalho, é o elemento que mais tem influência no cotidiano profissional (Lunardi et al, 2009). Desta forma, frente aos problemas éticos que são sistemáticos, o sofrimento moral surge como um fenômeno que deve ser visto a partir da perspectiva da organização, pois advém, na maior parte dos casos, de situações práticas de como ou qual a justificativa para realizar uma tarefa prescrita por outro, apesar de oposições em normas ou do senso coletivo. Assim, é preciso olhar para o sofrimento moral não somente como uma resposta de uma categoria profissional ou de indivíduos.

Dentre as possíveis estratégias para minimizar o sofrimento moral, sugerem-se discussões com temas relacionados à ética entre os trabalhadores, criação de protocolos de ações éticas, aproximação entre equipe de enfermagem, equipe médica e familiares (Lunardi et al, 2009).

Abordando o trabalho da enfermagem Merlo, Traesel e Baierle (2011) relatam que dentro dos hospitais há o trabalho imaterial, no qual há profundo investimento afetivo e aplicação da subjetividade, inteligência e dedicação do sujeito que o executa. Quando se trata de atendimento hospitalar, mais que dedicação do intelecto, é necessário um engajamento pessoal que envolve cuidado e carinho. Assim, este trabalhador oferece mais que seu corpo e tempo como instrumento de trabalho, ele se doa como o próprio instrumento. "Hoje é a alma do operário que deve descer à oficina. É a sua personalidade, a sua subjetividade, que deve ser organizada e comandada. Qualidade e quantidade do trabalho são reorganizadas em torno de sua imaterialidade" (Lazzaratto e Negri, 2001, p. 25). O tempo já não é dividido entre trabalho e vida pessoal, ele é permeável, existe um autocontrole que para além de exigências externas detém esse profissional a não parar de se doar as atividades que se propôs atuar. Este 
trabalhador hospitalar contemporâneo se coloca em uma posição de gestor de si, na busca por um sucesso inatingível que o leva muitas vezes ao esgotamento físico e psíquico.

Através da pesquisa com enfermeiros dentro do hospital e uma guarda municipal Merlo, Traesel e Baierle (2011) identificam nos enfermeiros muita exigência e dedicação, exemplificadas em falas como. "A gente é um pouquinho de cada profissional (...), acaba indo além. É uma das profissões mais desgastantes que existe (...). É o primeiro profissional a ser chamado dentro do hospital (...) somos pau pra toda obra". E ainda: "temos que ser sempre perfeitos (...) temos que dar conta de tudo, afinal somos enfermeiros". Nesta mesma pesquisa as enfermeiras relatam o amor pela profissão:

\footnotetext{
"Amo muito meu trabalho, muito mesmo, trabalho muito por amor ao que faço, (...) não mudaria de profissão. Trabalho muito mesmo e nem percebo, não paro pra pensar (...) vou trabalhando muitas horas porque gosto (...) só me preocupo com a minha família porque não tenho tempo para eles”. (Merlo, Traesel e Baierle, 2011, 98-99).
}

Tais frases denotam uma dedicação muito grande, assim como um processo de engajamento subjetivo muito forte, o que pode levar esses trabalhadores a um dilema paradoxal onde a demanda exaustiva de trabalho é banalizada e negligenciada pelos mesmos; onde não há tempo para problematizar seu próprio lugar neste trabalho. "Não aguento mais, mas é assim mesmo (...) não sei se estou feliz, se estou triste, só sei que eu trabalho e trabalho muito mesmo, até doente (...) a gente esquece da gente mesmo" (Merlo, Traesel e Baierle, 2011, p.99).

No artigo intitulado Sofrimento moral no cotidiano da enfermagem: traços ocultos de poder e resistência, de autoria de Barlem, Lunardi, Lunardi, Tomaschewski-Barlem \& Silveira (2013), os autores realizam uma pesquisa qualitativa junto a cinco enfermeiros, seis técnicos de enfermagem e quatro auxiliares de enfermagem que atuam em um hospital universitário localizado ao sul do país, em busca de conhecer as estratégias de resistências que esses trabalhadores adotam frente ao sofrimento moral. Para a análise dos dados, os autores abordam a temática do sofrimento moral através de duas categorias de análise, denominadas: "negação de si e do outro" e "possibilidades de cuidado de si e do outro".

$\mathrm{Na}$ primeira, aparecem falas que sinalizam situações que desencadeiam o sofrimento moral (SM), relacionadas à alta demanda de serviço e profissionais insuficientes para realizalo, o que gera sobrecarga de trabalho e a necessidade de priorizar atendimentos, ou seja, pacientes, em detrimento de outros. Além disso, aparecem estratégias individuais de enfrentamento, que auxiliam na "aceitação frente a situações que desencadeiam a vivência do 
SM, numa aparente negação de si e dos próprios valores” (Barlem et al, 2013, p. 4), por meio da aceitação de práticas profissionais que são julgadas como inadequadas ou contrárias aos valores dos trabalhadores, mas que atuam como defesas frente à situação. Assim, os autores defendem a existência de uma imagem profissional relacionando a enfermagem ao sacrifício e sofrimento, exemplificada na fala de um dos participantes, quando relata que "sempre tentei superar de algumas formas, como deixar de ter horário de descanso para realizar todas as atividades (E5)" (Id. Ibid), de maneira que a aceitação desses fatos naturaliza as vivências de sofrimento moral.

$\mathrm{Na}$ segunda categoria, possibilidades de cuidado de si e do outro, aparecem estratégias de enfrentamento e resistência ao sofrimento moral, utilizadas pelos trabalhadores, que passam, sobretudo, por "reuniões, mudanças de protocolos e de rotinas, e busca por qualificação profissional” (Barlem et al, 2013, p. 4). Adicionalmente, os autores citam a criatividade e iniciativa desses trabalhadores como fatores que fortalecem o senso de equipe e que possibilitam que haja uma mobilização para denunciar situações moralmente incorretas, que expõem o trabalhador ao sofrimento moral, exemplificada na seguinte fala: "Se eu não tenho um pacote de gaze, a primeira reação que eu tenho é de raiva. "Poxa, eu não tenho um pacote de gaze!”, aí depois tu paras para pensar e vira indignação.” (Id. Ibid).

Ainda, diante da percepção da transgressão de valores morais, de fragilização do cuidado dispensado aos pacientes, e de dificuldades de enfrentamento dos sujeitos envolvidos nessas situações, alguns trabalhadores, a partir de um processo reflexivo e como uma prática de cuidado de si, optam por se afastar desses ambientes de trabalho. (Barlem et al, 2013, p. 5).

Essa constatação dos autores pode ser evidenciada na fala de um dos participantes da pesquisa:

\footnotetext{
"Para conseguir aliviar e voltar no próximo plantão eu só enxergava aqueles pacientes que realmente precisavam. Para esses pacientes eu me dedicava mais e desenvolvia mais o meu conhecimento e então me sentia um pouco melhor". Tal argumento foi utilizado para descrever o quanto o número reduzido de profissionais na equipe somado a uma grande demanda de trabalho levava ao sofrimento moral, onde ocorriam priorizações de atendimentos, em detrimento de outros. Em outro relato: "Tu chegas pra trabalhar e falta material; aí muita gente, infelizmente isso é da nossa cultura da enfermagem, muita gente tem o material, mas guarda nas suas coisas, guarda nos seus armários, dizendo " $\mathrm{Ah}$ ! Não pode, se eu não guardar vai faltar pra mim".
}

Desta forma é possível identificar como os sujeitos vivenciam situações que o expõem ao sofrimento moral e como ocorre a externalização passível de ser observada pelo seu colega de trabalho. Na categoria negação de si e do outro, "percebe-se a aceitação e conformismo 
com práticas do cotidiano profissional, mesmo que reconhecidas como inadequadas (...)" (Barlem al, 2013, p.4).

Por meio destas falas e análises, podemos entender que são expressas vivências do sofrimento ético, conforme proposto por Dejours, visando a uma produtividade extrema, entrega física, psíquica, ética e moral do indivíduo. Além disso, são sinalizadas falas e estratégias que podem exemplificar o que Beck (2000) destaca em sua tese como mecanismos que os trabalhadores, diante de situações com grande sofrimento, utilizam para a sua defesa, como a sublimação e a negação, que levam o sujeito a evitar ou não enfrentar os problemas no âmbito profissional e a banalização do sofrimento. Traesel (2007) ressalta em seu artigo que a grande dedicação e o volume de trabalho levam a extrapolação da exigência humana de tempo doado, o que interfere diretamente na vida deste trabalhador, por vezes confundido com maquinas que estão configuradas a não sentir.

$\mathrm{Na}$ literatura que amplia o público pesquisado para além de profissionais da enfermagem, podemos situar a pesquisa de autoria de Bottega e Merlo (2017), que se trata da realização de uma clínica do trabalho no SUS, com 24 participantes, dentre os quais 13 são da área da saúde. A partir da demanda espontânea dos trabalhadores no Ambulatório de Doenças do Trabalho do Hospital de Clínicas de Porto Alegre, eles foram entrevistados, responderam ao Self-Reporting Questionnaire (SRQ-20) e foram atendidos na perspectiva da Clínica Psicodinâmica do Trabalho. Os autores organizam seus resultados em cinco grupos temáticos, e para esta pesquisa destacamos o grupo Gestão.

As análises realizadas apontam para situações de assédio moral, violência psicológica e assédio de colegas, contendo situações de "exposição a situações vexatórias na frente de colegas, exposição de situações particulares, pedidos de não comunicação, ameaças (...), atitudes de xingamentos e humilhações” (Bottega e Merlo, 2017, p.7). Tais práticas podem ser entendidas como causadoras de vivências de sofrimento ético nos trabalhadores, e, por ser fruto de atendimentos aos trabalhadores com sofrimento/adoecimento psíquico, indicam $\mathrm{O}$ potencial patogênico dessas situações engendradas pela organização e sua gestão sobre a saúde mental dos profissionais atendidos. Segundo os autores, essa experiência realça que a escuta clínica das questões relativas ao trabalho ajuda a elaborar a violência sofrida, e um reposicionamento mais ativo frente à situação relatada/vivenciada, além de amenizar o sentimento de solidão. Dessa maneira, entendemos que essa prática clínica se configura como uma importante estratégia de enfrentamento ao sofrimento ético e adoecimentos decorrentes das situações de trabalho propiciadoras de conflitos e dilemas éticos. 
Como vimos, as estratégias de enfrentamento podem ser coletivas ou individuais, mas, de forma mais comum, os trabalhadores que experienciam situações causadoras de sofrimento ético podem sentir-se sozinhos. Existe uma "solidão própria da sociedade contemporânea" (Nardi, 2003, p. 53), que, através de rotinas exaustivas e ritmos de trabalho acelerados, corrobora para uma menor interação pessoal entre o trabalhador e seus pares, às vezes criando um ambiente extremamente individualizado de competição e inimizades. Na tentativa de dar conta de si, sem interação com o outro, é instaurado um ambiente sem margem para reconhecimento mútuo, o que salienta um individualismo acima da solidariedade entre seus pares (Traesel, 2007). Ao expressar o que sentem durante a prática clínica como exposto na pesquisa de Bottega e Merlo, ou nos espaços de discussão presentes na própria organização do trabalho, conforme apostamos, os espaços individuais e as discussões coletivas possibilitam a estes profissionais se enxergarem como sujeitos com sentimentos, desejos e anseios. O falar sobre e ouvir faz com que o profissional enfrente e desnaturalize o seu sofrimento, o leva a transformar o sofrimento em algo criativo, além de gerar novas formas de defesa e/ou enfrentamento (Dejours, 2004).

\section{Considerações finais}

Através das reflexões abordadas no presente trabalho foi possível a articulação do tema com bases teóricas pertinentes e importantes para compreensão do que é o sofrimento ético e moral e como atingem as práticas dos profissionais da enfermagem. Por meio de estudos advindos da Psicodinâmica do Trabalho, sobretudo de Dejours, destacam-se a relação homem-trabalho e os impactos psíquicos inseridos nesta relação. Ao estabelecer o conceito de sofrimento ético, é possível fazermos uma leitura das pesquisas que abordam o sofrimento moral e aproximarmos os conceitos, preservando suas diferenças epistemológicas.

O presente artigo retrata um sujeito permeável, que não é passível de divisões psíquicas entre trabalho e vida pessoal. Conforme a teoria da Psicodinâmica, esse sujeito possui desejos, crenças e história que perpassam suas relações de trabalho, num movimento de dupla influência. A organização do trabalho e as defesas e mobilizações utilizadas pelos trabalhadores diante do sofrimento inerente ao trabalhar constituem situações complexas para análise que, diante de um olhar cuidadoso e criticamente treinado, pode auxiliar na busca pela saúde por parte dos trabalhadores. As intervenções nas situações de trabalho devem considerar a experiência dos trabalhadores, ou corre-se o risco de perpetuar discursos e 
práticas que vitimizam os trabalhadores e os tomam como únicos responsáveis pelas questões éticas que perpassam o trabalhar, ou ainda, como recursos para práticas de acumulação.

Destaca-se, conforme Merlo, Traesel e Baierle (2011), que na contemporaneidade o trabalho do profissional de saúde, e, em nosso caso, o trabalho dos profissionais de enfermagem, envolve uma complexidade grande. Além dos seus resultados expressos nos corpos dos pacientes e passíveis de observação, é possível identificar que o trabalho do profissional da saúde é também imaterial. Assim, este trabalho imaterial engaja além do intelecto, a doação de afeto como instrumento de trabalho; são sujeitos trabalhadores que disponibilizam tempo e afeto e cujo resultado é parcialmente invisível (Dejours, 2004a).

Por meio de pesquisas bibliográficas encontramos profissionais que expressam em suas falas o sofrimento com que se deparam frente ao cotidiano de seu trabalho. Ao engajarem-se com sua subjetividade numa situação de grande vulnerabilidade e intensidade de trabalho, desconsiderando limites que preservem a sua saúde e em busca de resultados cada vez maiores, como o atendimento de um maior número de pessoas, a administração de tarefas gerenciais e das tensões da gestão coletiva do trabalho, esses trabalhadores podem estar passíveis de vivenciar o sofrimento ético. Em algumas ocasiões, utilizam-se de estratégias defensivas para não se confrontarem intelectualmente com os impactos desse sofrimento sobre sua saúde e subjetividade.

Ao analisar as possíveis intervenções com intuito de auxiliar esses profissionais, deparamo-nos com a escuta clínica, que pode ser realizada de forma individual ou em grupo com o propósito de auxiliar o sujeito a se posicionar de forma mais ativa frente às questões negligenciadas pelos próprios individuo imerso aos afazeres do trabalho. Conforme nos relatam Bottega e Merlo (2017), essa escuta pode auxiliar no enfrentamento do sentimento de solidão, típico de quem vivência esse sofrimento. Outra intervenção interessante, amplamente ancorada na perspectiva da Psicodinâmica, é a oferta de espaços coletivos de discussão sobre o trabalho, que envolvam a expressão das vivências e também dos afetos, de maneira a propiciar a emergência da cooperação entre o coletivo. Para tanto, é necessária uma postura ética para lidar com esse "real do mundo social" (Dejours, 2004a, p. 31).

Por meio da metodologia utilizada nesta pesquisa, obtivemos pouca literatura que abordasse de forma explícita a temática do sofrimento ético, o que nos demonstra necessidade de aprofundamento de estudos dentro desta área de pesquisa. Diante disso, considera-se que Lins, Vasconcellos e Palacios (2015) fazem uma importante contribuição à temática ao aproximarem as áreas relativas à Saúde do Trabalhador à Bioética, propondo uma "abordagem ética sobre a relação saúde-trabalho", buscando considerar a construção de 
intervenções e conhecimentos coletivamente, ou seja, levando em consideração o "interesse de todos os afetados, a partir da ampliação do papel dos próprios trabalhadores nesse processo" (Lins, Vasconcellos e Palacios, 2015, p.294).

A partir dessa construção ética sobre a díade trabalho-saúde, estudada em diferentes disciplinas e sob lógicas diferentes pode-se constatar avanços no campo da saúde do trabalhador em relação à medicina do trabalho e da saúde ocupacional, sobretudo na consideração dos trabalhadores como protagonistas no seu processo de saúde e adoecimento. Com base nessa perspectiva de estudo, ressalta-se que não se trata de individualizar a questão, apontando então para o primado das características individuais, mas considerar o movimento relacional entre as subjetividades engajadas e a organização das situações de trabalho, de maneira a problematizar também "a eticidade das relações que fazem emergir os problemas" (Lins, Vasconcellos e Palacios, 2015, p.297).

Conclui-se que os profissionais de enfermagem, na busca incessante pela excelência profissional, mobilizam grande parte da sua subjetividade ao engajarem-se no trabalho, ao ponto de realizarem tarefas que moralmente não aceitam, o que os leva ao sofrimento ético e moral. Esse sofrimento faz parte do cotidiano destes sujeitos, reforçado por relações de trabalho adoecedoras, além de um local de atuação que dificulta a comunicação e a convivência entre os colegas, gerando assim, uma dor profunda e silenciosa capaz de levar ao adoecimento. Sobre os efeitos do SM (sofrimento moral), os estudos de Barlem apontam seus efeitos no cotidiano laboral da enfermagem: "Seja agindo e reagindo, seja se omitindo, os profissionais de enfermagem manifestam desconforto quando reconhecem não executar as ações que acreditam serem as mais corretas, vivenciando os efeitos do SM, mesmo podendo não identificá-los como tal" (Barlem et al, 2013, p. 5). Ainda nesse sentido, os autores reforçam que, ao lidar com situações que condenam moralmente e que causam a vivência de sofrimento ético, "os profissionais de enfermagem aparentemente optam não por se evadirem da profissão, mas de seus valores e, por fim, dos próprios ideais da enfermagem” (Id. Ibid).

Essas situações, caracterizadas pela presença maciça de sofrimento ético ou patogênico podem, a partir de intervenções nas situações de trabalho, se reconfigurarem, de maneira a diminuir a presença destes, abrindo espaço para o sofrimento criativo, possibilitando que o trabalho contribua mais para a saúde do que para o adoecimento dos trabalhadores.

As intervenções, portanto, amparadas nos campos da saúde do trabalhador, na bioética e na Psicodinâmica do Trabalho devem buscar construir processos transformadores no mundo do trabalho, realçando o papel de protagonista dos trabalhadores e a luta política que se faz 
necessária na disputa para implantação de práticas e conhecimentos de formas de trabalho e gestão não hegemônicas, inclusivas e promotoras de saúde. Essa disputa de poder, realizada a todos os instantes em diversos locais, pode ocorrer nos campos da pesquisa, como se pretende com este trabalho, no campo prático, a partir de profissionais que possam mediar as relações de trabalho de modo mais humano e ético ou, preferencialmente, de forma coletiva e interdisciplinar.

Dessa maneira, abordar o sofrimento ético no trabalho da enfermagem poderá permitinos superar o primado da saúde da produção (ética empresarial ou discurso neoliberal) sobre a saúde do trabalhador ao impulsionar os ideais e princípios éticos e morais que fundamentam o saber fazer do trabalhador da saúde e seu potencial de refletir e agir coletivamente sobre seu trabalho. Acreditamos, assim, que ao dar visibilidade ao sofrimento ético em sua interface com o contexto de trabalho, em especial do trabalho da enfermagem, torna-se possível abrir espaços para a criação de um novo tecido social que potencialize práticas profissionais mobilizadoras de estratégias de enfrentamento a esse sofrimento, minimizando suas consequências sobre a saúde e possibilitando a escolha de práticas profissionais que sustentem a humanização, os ideais profissionais e o sentido do trabalho na enfermagem.

\section{Referências}

Barlem, E., Lunardi, V., Lunardi, G., Tomaschewski-Barlem, J.\& Silveira, R. (2013/ Janeiro/Fevereiro). Sofrimento moral no cotidiano da enfermagem: traços ocultos de poder e resistência. Revista Latino-Americana de Enfermagem, 21(1), 8 telas. Recuperado de: http://www.scielo.br/pdf/rlae/v21n1/pt_v21n1a02.pdf.

Beck, C. L.C. (2000). O sofrimento do trabalhador: da banalização à re-significação ética na organização da enfermagem (Tese de Doutorado, Centro de Ciências da Saúde. em Enfermagem, Universidade Federal de Santa Catarina). Recuperado de: https $: / /$ repositorio.ufsc.br/xmlui/bitstream/handle/123456789/78333/153135.pdf? sequenc e=1\&isAllowed=y.

Bottega, C. G. \&Merlo, A. C. (2017). Clínica do trabalho no SUS: possibilidade de escuta aos trabalhadores. Psicologia \& Sociedade, 29, 1-11. Recuperado em: http://www.scielo.br/pdf/psoc/v29/1807-0310-psoc-29-e156376.pdf.

Cerqueira, H. G. (2006) Sobre a filosofia moral de Adam Smith. Anais do XXXIV Encontro Nacional de Economia, Salvador, BA, Brasil. Recuperado de: http://www.anpec.org.br/encontro2006/artigos/A06A039.pdf.

Dalmolin, G. L., Lunardi, V. L., Lunardi, G. L., Barlem, E. L. D., \& Silveira, R. S. (2014, Janeiro/Fevereiro). Sofrimento moral e síndrome de Burnout: existem relações entre esses 
fenômenos nos trabalhadores de enfermagem? Revista Latino-Americana de Enfermagem, 22(1), 1-8. Recuperado de: http://www.scielo.br/pdf/rlae/v22n1/pt 01041169-rlae-22-01-00035.pdf.

Dejours, C. (1999). Violence ou domination? Travailler,3, 11-29. Recuperado de: http://www.comprendre-agir.org/images/fichierdyn/doc/violence domination_dejours.pdf.

Dejours, C. (2004a, Setembro/Dezembro). Subjetividade, trabalho e ação. Revista Produção. 14(3), 27-34. Recuperado de: http://www.scielo.br/pdf/prod/v14n3/v14n3a03.pdf.

Dejours, C. (2004b) Addendum - Da psicopatologia à psicodinâmica do trabalho. [Tradução de FranckSoudant] In Lancman, S. e Sznelwar, L. I. (Orgs.), Christophe Dejours: da psicopatologia à psicodinâmica do trabalho. (pp. 47-104). Rio de Janeiro: Editora Fiocruz, Brasilia: Paralelo 15.

Dejours, C. (2006). O trabalho entre sofrimento e prazer. In: Dejours, C. A banalização da injustiça social. (7a ed., Cap. 2, pp. 27-36). Rio de Janeiro: Editora FGV.

Dejours, C. (2007). A psicodinâmica do trabalho na pós-modernidade. In: A. M. Mendes, S. Z. Cruz Lima, \& E. P. Facas (Orgs.), Diálogos em Psicodinâmica do Trabalho. (pp. 1326). Brasilia: Paralelo 15.

Freud, S. (1974). O mal-estar na civilização. (J. Abreu, Trad., Edição Standard Brasileira das Obras Psicológicas Completas de Sigmund Freud, v. XXI). Rio de Janeiro: Imago.

Fruet, I. M. A., Dalmolin, G. L., \&Speroni, K. S. (2017, Abril/Junho). Instrumentos de avaliação do sofrimento moral em trabalhadores de enfermagem: revisão integrativa.Revista de Enfermagem da UFSM, 7(2), 314-326. Recuperado de: https $/ /$ periodicos.ufsm.br/reufsm/article/view/20716.

Houaiss, A. (2001). Dicionário Houaiss da Língua Portuguesa. Rio de Janeiro: Objetiva.

Kant, I. (1964). Fundamentação da Metafísica dos Costumes. São Paulo: Companhia Editorial Nacional.

Kant, I. (1989). Crítica da razão prática. Lisboa: Edições 70.

Lazzaratto, M. \& Negri, A. (2001). Trabalho imaterial: formas de vida e de produção de subjetividade. Rio de Janeiro:DP\&A.

Lins, T., Vasconcellos, L. C. F. \& Palacios, M. (2015). Bioética e saúde do trabalhador: uma interface. Revista bioética, 23(2), 293-303. Recuperado de: http://www.scielo.br/pdf/bioet/v23n2/1983-8034-bioet-23-2-0293.pdf.

Lunardi, V. L., Barlem, E. L. D., Bulhosa, M. S., Santos, S. S. C., Filho, W. D. L., Silveira, R. S., Bao, A. C. P., \&Dalmolin, G. L. (2009, Julho/Agosto). Sofrimento moral e a dimensão ética no trabalho da enfermagem. Revista Brasileira de Enfermagem, 62(4), 599-603. Recuperado de http://www.scielo.br/scielo.php?script=sci_arttext\&pid=S003471672009000400018. 
Martins, S. R. (2009) Clínica do trabalho.São Paulo: Casa do Psicólogo. Coleção clínica psicanalítica.

Martins, S. R., Moraes, R. D., \& Cruz Lima, S. C. (2010). Sofrimento, defesa e patologia: o olhar da Psicodinâmica sobre a violência no trabalho. A. M. Mendes (Org.), Violência no trabalho: perspectivas da psicodinâmica, da ergonomia e da sociologia clínica. (pp. 1939). São Paulo: Universidade Presbiteriana Mackenzie.

Maturana, H. (2002). Emoções e linguagem na educação e na política. Belo Horizonte: Ed. UFMG.

Mendes, A. M. (1995).Aspectos psicodinâmicos da relação homem-trabalho: as contribuições de C. Dejours. Psicologia. ciência e profissão.15(1-3), 34-38. Recuperado de: http://www.scielo.br/pdf/pcp/v15n1-3/09.pdf.

Mendes, A. M. (2007). Da psicodinâmica à psicopatologia do trabalho. In Mendes, A. M. (Org.), Psicodinâmica do trabalho: teoria, método e pesquisas. (pp. 29-48). São Paulo: Casa do Psicólogo.

Mendes, A. M., Costa, V. P., \& Barros, P. C. R. (2003). Estratégias de enfrentamento do sofrimento psíquico no trabalho bancário. Estudo e Pesquisas em Psicologia. 3(1), 38-48. Recuperado de publicacoes. ueri.br/index.php/revispsi/article/view/7778/5626.

http $/ /$ www.e-

Merlo, A. R. C.; Traesel, E. S.; Baierle, T. C. (2011). Trabalho imaterial e contemporaneidade: um estudo na perspectiva da Psicodinâmica do Trabalho. Arquivos Brasileiros de Psicologia, 63(no. spe.),94-104. Recuperado em: http://pepsic.bvsalud.org/scielo.php?script=sci_arttext\&pid=S1809-52672011000300010.

Moraes, R. D. (2013). Sofrimento criativo e patogênico. In F. O. Vieira, A. M. Mendes \& A. R. C. Merlo (Orgs), Dicionário crítico de gestão e psicodinâmica do trabalho (pp. 415419). Curitiba: Juruá.

Nardi, H. C. (2003. Janeiro/Junho). A propriedade social como suporte da existência: a crise do individualismo moderno e os modos de subjetivação contemporâneos. Psicologia \&Sociedade. 15(1), 37-56. http://www.scielo.br/pdf/psoc/v15n1/v15n1a04.pdf.

Saccol, A. Z. (2009). Um retorno ao básico: compreendendo os paradigmas de pesquisa e sua aplicação na pesquisa em Administração. Revista de Administração da UFSM, 2(2), 250269. Recuperado de: https://periodicos.ufsm.br/reaufs m/article/view/1555/863.

Santos, B. S. (2007). Para além do pensamento abissal: das linhas globais a uma ecologia de saberes. Novos Estudos, 79, 71-94. Recuperado de: http://www.scielo.br/pdf/nec/n79/04.pdf.

Smith, A. (2002) Teoria dos sentimentos morais. São Paulo: Martins Fontes.

Traesel, E. S. (2007) A psicodinâmica do reconhecimento: Sofrimento e realização no contexto dos trabalhadores da enfermagem de um hospital do interior do Rio Grande do Sul. (Dissertação de mestrado, Instituto de Psicologia, Universidade Federal do Rio Grande do Sul). Recuperado de 
https://ume.ufrgs.br/bitstream/handle/10183/10099/000595302.pdf?sequence=1\&isAllo $\underline{w e d}=\mathrm{y}$.

Vasconcelos, A. C. L. (2013). Sofrimento ético. In F. O. Vieira, A. M. Mendes \& A. R. C. Merlo (Orgs), Dicionário crítico de gestão e psicodinâmica do trabalho (pp. 421-425). Curitiba: Juruá.

Vaz, H. C. L. (1999) Escritos de Filosofia IV: Introdução à ética filosófica 1. São Paulo: Ed. Loyola. 